\title{
Relationship between City and Energy Based on Economics Theory
}

\author{
Mingsheng Li \\ China National Environmental Monitoring Center, Beijing 100012, China \\ Email: lims@cnemc.cn
}

Keywords: relationship; city; energy; economics theory; environment

Abstract. In order to investigate the relationship between city and energy, three types of relationship, including relationship between energy and resident life, relationship between energy and urban growth and relationship between energy and environment in a city, was established in accordance with economic theory. The results can be summarized as follows. (1) One energy resources can be replaced by another energy resources and the pattern of consuming energy resources is not always optimum in actual life. (2) energy consumption and energy structure adjustment could promote urban economic growth and urban population growth. (3) Consumers would like to choose inexpensive energy, instead of choosing environment friendly energy, because the environment friendly energy usually is expensive. In order to promote urban growth rapidly and urban environment livable, government should provide subsidy to new energy consumer and raises the price of polluted energy to eliminate the externalities.

\section{Introduction}

Nowadays, people face more serious energy shortage problem. The existing paradigm of technology bring two outcomes, one is relaying on energy, and the other is the world is subject to the west world. If developing country wants to change the fact, it must be given a lesson. From the point of view of Asia, Japan still the third biggest country in economy. Though it has adopted lots of technology that economizes scarce energy resources, it is still an important consumer of energy because of recovering the time wasted in economy. In a word, the changing of economic pattern of the world, must give the previous one an impact, as a result, contesting with each other for energy must be fierce. From seeing at domestic, economy growth at a top speed lasts more than 30 years. At the same time, China become a large consumer of energy. Besides the reason of economy growth, there are some other reasons, such as the pattern of produce, Property Rights, etc. According to a short time, the domestic demand was not matching domestic supply, and gap between demand and supply require foreign to offset. As the price of oil rises, the demand of foreign must deduct, so that there will be surplus in home market. All in all, energy is a serious problem. It concerns the national economy and the people's livelihood.

Urban is a symbol of progress of humankind, and urban is the core of a region. In fact urban controls the current of energy, material and information, and the centralization make urban the important consumer of energy. The fact that urbanization is in proportion to economy suggest that the urbanization must continue, so more energy will be required.

There are few studying on relationship between energy and city at home and abroad, and most studies explored the relationship between urban expansion and energy consumption [1,2], urban energy efficiency measurement [3,4], urban energy use and $\mathrm{CO}_{2}$ emissions [5,6], urban development and energy consumption [7], urban energy consumption and effect on environment [8,9], urban planning and energy efficiency [10], urban building and energy utilization [11], etc. It can be found out from above analysis that the most studying of energy only referred to some phenomena, but not the mechanism that interprets why urban and energy can promote mutually. In fact, this paper just attempts to resolve the problem. 


\section{Relationship between Energy and Resident Life}

As the income increases, residents will want to live a good life and require more clean energy. However, some existing data doesn't support it apparently. The reason lies in technology of economizing energy. As the income increases, residents prefer to durable goods which consume clean energy. However, clean energy is more expensive and not available sometimes. Take coal for example, the volume of coal in terminal energy consumption is 6.38\% in Japan, 9.06\% in South Korea, 3.76\% in France, 5.08\% in German, and 1.87\% in America in 1996。 However, it is 66.0\% in China in 2013. In generally speaking, geographical position influences the volume and type of energy resources. There are seldom urban that are rich not only in property but also in energy resources. So the problem of energy becomes more complex.

Suppose energy resource 1 can be only used for getting warm, and energy resource 2 can be only used for light. So above two energy resources substitute each other incompletely. On the contrary, some energy resources can substitute each other completely. The reason lies in technology and the cost of consuming some resource which can give people a special utility.

Left figure of Fig. 1 shows the case of incomplete substitution, and right figure of Fig. 1 shows complete substitution. In Left figure, the optimum option is $\mathrm{E}$ where the Cost is minimization or utility is maximization. At this point, residents consume some energy resource 1 and some energy resource 2. In right figure, because the indifference curve is a line, the optimum option is E'. At this point, residents only consume energy resource 2 . The reason is that the price of energy resource 2 is lower.

a

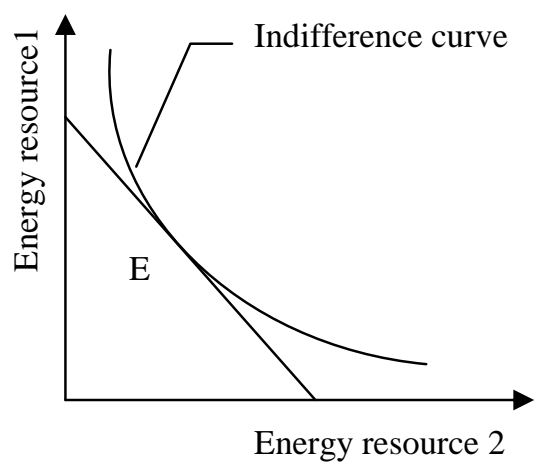

$\mathrm{b}$

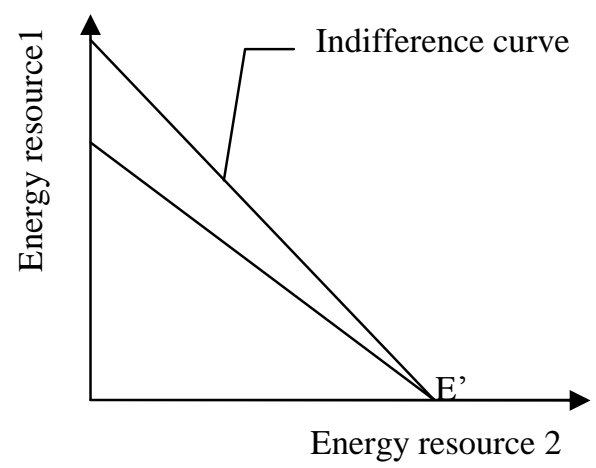

Fig. 1 Indifference curve of two incomplete (a) and complete (b) substitution energy resources

In actual life, energy cannot give consumer some utility alone. It may combine with some facility for getting some special utility, and consumers must choose a special one because the prices of different energy resources are not same. As a result, the price of energy resource which gives some special utility differs. Even if every energy resources can substitute each other complete, in actual life, there must be many types of energy resources, such as natural gas, coal, oil, and electricity, etc. As technology progresses, the pattern of using energy changed constantly, and sometimes some change create a new paradigm of technology, inaugurate a new era.

In our actual life, an example of changing is that the type of fuel of motorcars changes. As the price of petroleum increasing, some taxis don't use petroleum again, and change to use gas. The reason is the price of gas is lower than the one of petroleum. Why do they not use gas for taxis before? The reason lies in technology and the user cost. A long, long time ago, there were no technology that made taxi drivers decide to change fuel from petroleum to gas, so the taxi drivers had only one choice. Someday people get the technology, why they not use it? The reason is the cost is relatively high. Suppose the price of petroleum is $\mathrm{P}_{1}$, and the volume of consuming is $\mathrm{X}$; on the other hand, the price of gas is $\mathrm{P}_{2}$, and the volume of consuming is $\mathrm{X}$, too. Given the cost of change is $\mathrm{C}$, and it is $\mathrm{n}$ years before the machine is useless, how much does the taxi drivers gain from the changing? Suppose $\pi$ represents the gain, then the gain is as below: 


$$
\pi=\left(P_{1} X-P_{2} X\right) /(1+r)^{0}+\left(P_{1} X-P_{2} X\right) /(1+r)^{1}+\mathbf{L}+\left(P_{1} X-P_{2} X\right) /(1+r)^{n}
$$

In Eq. $1, r$ is interest rate. If $\pi \geq \mathrm{C}$, the taxi drivers may decide to change.

Now suppose the utility function of the consumer is below

$$
U=X^{\alpha} Y^{\beta}
$$

In Eq. 2, $X$ is common goods, and $Y$ is energy. We can get the demand function as below:

$$
P_{Y} \times Y=\beta \times m /(\alpha+\beta)
$$

Suppose supply of energy resource 1 is constant in short time, and price is constant, too. If the demand of the energy resource increases, due to constant supply, the profit will be damaged. In Fig. 2, the initial equilibrium is $\mathrm{E}$, where volume of energy resource 1 is $\mathrm{Q}_{0}$, and price is $\mathrm{P}$. As the demand increases, the new equilibrium is $\mathrm{E}^{\prime}$ where volume is $\mathrm{Q}_{1}$, and price is $\mathrm{P}$, too. However, as the energy resource 1 is scarce, so the gap between $\mathrm{Q}_{0}$ and $\mathrm{Q}_{1}$ can not be gotten, and the volume of the losing of the consumer surplus is as big as the area of the shadow. If a feasible technology of changing type of fuel from energy resource 1 to energy resource 2 is gotten, the losing of the consumer surplus can be avoidable.

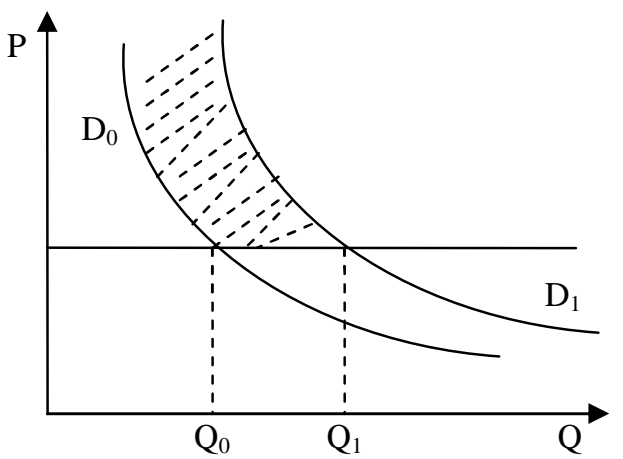

Fig. 2 Supply and demand curves of energy

Through above analysis, we can draw a conclusion as following: 1) Most energy resource are normal goods, and the more energy consumed, the more utility gained. 2) As the technology progresses, the cost of changing becomes lower and lower; 3) Due to the existence of the cost, the pattern of consuming energy resources is not optimum in actual life. 4) The government should try to decrease the cost of change and increase the consumer surplus.

\section{Relationship between Energy and Urban Growth}

Economists consider capital (K) and labor (L) are material to economic growth. With the coming of knowledge economy, economists think the development of technology is crucial, so they add it to the former factors which render economy to grow. Afterward somebody consider the energy should be included, too. A typical case is that Tang etc [12] use Cobb-Douglas Function to interpret the economic growth. In Eq. 4, energy is regarded as the same status as capital or labor.

$$
\mathrm{Y}=\mathrm{A}_{\mathrm{i}}\left(1+\lambda_{\mathrm{i}}\right)^{\mathrm{T}} \mathrm{K}_{\mathrm{it}}^{\alpha \mathrm{i}} \mathrm{L}_{\mathrm{it}}^{\beta \mathrm{i}} \mathrm{E}_{\mathrm{it}}^{\gamma \mathrm{i}}
$$

In fact, the above equation is not always correct. Two reasons are as follows. First, capital and labor can substitute each other. However, energy cannot be substituted by capital or labor. Second, energy is the groundwork of capital and labor, and energy influences economy by influencing capital and labor. So the following equation is given to explain the relationships.

$Y=F(L, K, t)$

After we decompose the above equation, we can get a new equation as following. 
$(d Y / d t) / Y=(\partial F / \partial t) / Y+(\partial F / \partial L) \cdot(L / Y) \cdot[(d L / d t) / L]+$

$(\partial F / \partial K) \cdot(K / Y) \cdot[(d K / d t) / K]$

Another expression of Eq. 5 is the Eq. 7.

$Y=A(t) F(L, K)$

Then, Eq. 6 could be replaced by Eq. 8 .

$\Delta Y / Y=\Delta A / A+\alpha \Delta L / L+\beta \Delta K / K$

In Eq. 8, $\Delta Y / Y$ represents economic growth rate, $\Delta L / L$ is labor growth rate, $\Delta K / K$ is capital growth rate, $\alpha$ is the share which labor gains, and $\beta$ is the share of capital.

In relation to above equations, a new function is just as Eq. 9.

$Y=A(t) F(g \cdot L, e \cdot K)$

In Eq. $9, g$ is a function of $\mathrm{E}_{1}$, and $\mathrm{E}_{1}$ is the volume of energy for labor. The function is given as Eq. 10.

$g=\mathrm{g}\left(\mathrm{E}_{1}\right), g \subset(0,1), d g / d E_{1}>0$

In Eq. 9, $e$ is a function of $\mathrm{E}_{2}$, and $\mathrm{E}_{2}$ is the volume of energy for capital. The function is given as Eq. 11.

$e=\mathrm{e}\left(\mathrm{E}_{2}\right), e \subset(0,1), d e / d E_{2}>0$

From Eq. 9 we can find that intent of the new function is giving weighing to capital and labor respectively. In fact, if a unit of labor consume more energy, the quality of labor will be better. In the same way, if a unit of capital consume more energy, the quality of capital will be better, too. A city only having labor and capital is not enough, it must have plenty of energy. Nowadays, the scarce of energy do harm to produce seriously in some Chinese urban. In the last year some south urban in China have no plenty of electricity, and lot's of factory had to stop production. Another similar example is some north urban have to go through a chill winder due to scarce of gas for heating. Obviously there were capital and labor, but their production was subjected to some energy. We can draw a conclusion that the volume of capital or labor should multiply their weighing in order to get a genuine volume.

After we decompose Eq. 9 then get a new Eq. 12.

$$
\frac{\partial Y / \partial t}{Y}=\frac{d A / d t}{A}+\beta^{\prime} \cdot \frac{d K / d t}{K}+\alpha \cdot \frac{d L / d t}{L}+\beta^{\prime} \cdot \frac{d e / d t}{e}+\alpha \cdot \frac{d g / d t}{g}
$$

Change Eq. 12 by multiplying $\Delta t$, we can get Eq. 13 .

$$
\Delta Y / Y=\Delta A / A+\beta^{\prime}(\Delta K / K)+\alpha^{\prime}(\Delta L / L)+\beta^{\prime}(\Delta e / e)+\alpha^{\prime}(\Delta g / g)
$$

Where, $\beta$ ' is the gain of capital that is gotten by weighing multiplying initial volume of capital, and $\alpha^{\prime}$ is the share of labor after give weighing.

$$
\beta^{\prime}=(\partial Y / \partial K e) \cdot K e / Y ; \alpha^{\prime}=(\partial Y / \partial L g) \cdot L g / Y
$$

From Eq. 9 we can come to a conclusion that 5 factor can accelerate economic growth, that is, labor, capital, development of technology, energy for labor and energy for capital.

As we well know, we become aware of urban growth from three aspects, that is, economic growth, population growth and the growth of land-use scale in a city. Above studying based on the first aspect, we will discuss the relationship between the urban growth and the last two aspects.

The urban economy achieves general equilibrium when four conditions are satisfied simultaneously: 1) All firms make zero profit at all location. 2) All households achieve the same 
utility at all location city. 3) Land is allocated to the highest bidder. 4) The total demand for labor equals the total supply of labor.

If above conditions is satisfied simultaneously, we can get an equilibrium land-use pattern in a city like Fig. 3.

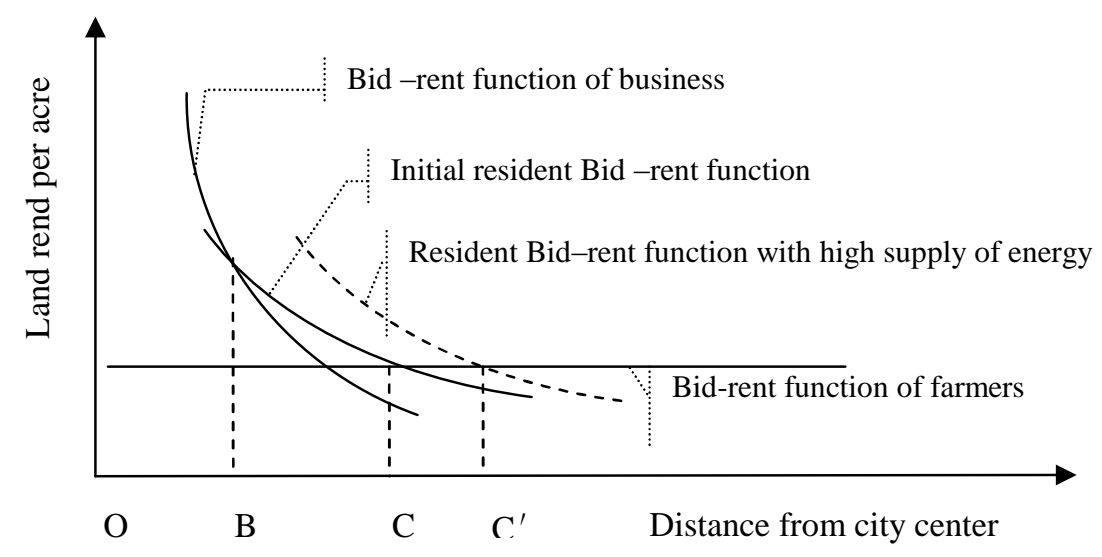

Fig. 3 The partial-equilibrium effect of an increase in supply of energy

Let's analyze Fig. 3. At the beginning, the bid-rent function of residents intersects the bid-rent function of farmer at point C. However, an increase in the supply of energy decreases the cost of residents or firms, then shifts the bid-rent function of residents and the bid-rent function of business upward, then the initial point of intersection $\mathrm{C}$ have a right shift, and get an another equilibrium at point C', so that two outputs are produced. First the area of city grows. Second, as the price of land increase, the density within urban increases, too. As a result, the urban population increases evidently.

In Fig. 4, suppose the brim of supply of energy at point $C$ at the beginning, why is not point $C$ ', where the Resident bid-rent function intersects the Bid-rent function of farmers? Maybe the reason is the government restricts the scare of urban, or at the point $C$ the cost of providing energy service is expensive relatively to gain, so doesn't supply energy. Of course we do not specially care about the reasons. Given government decides to supply energy at point $\mathrm{C}$, there will be two outputs, too. First the resident area in city grows. Second, as the price of land increase, the density within the resident area increases, too. As a result, the urban population increases.

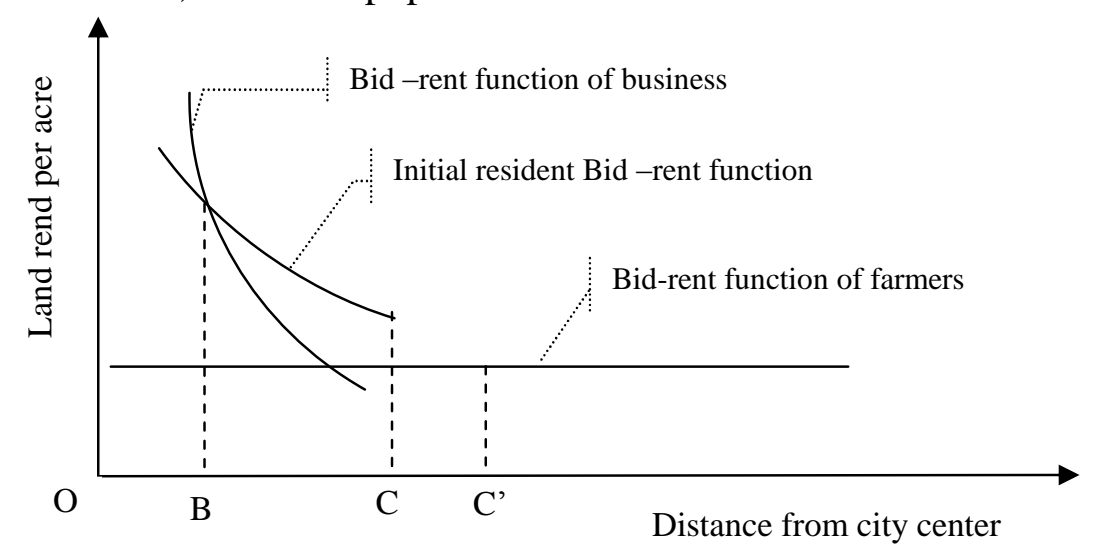

Fig. 4 The partial-equilibrium effect of a perfect supply of energy

Above discussion consider that an increase in supplying energy promotes urban growth. In fact, energy structure adjustment can also promote urban growth. An example that support it is clean energy means clean environment, and clean environment increase the population and the price of the land rent.

\section{Relationship between Energy and Urban Environment}

In Fig. 5, the budge line is Eq. 15. $\mathrm{P}_{1}$ is the price of coal, $\mathrm{P}_{2}$ is the price of electricity, and $\mathrm{m}$ represents expenditure of electricity and coal. 


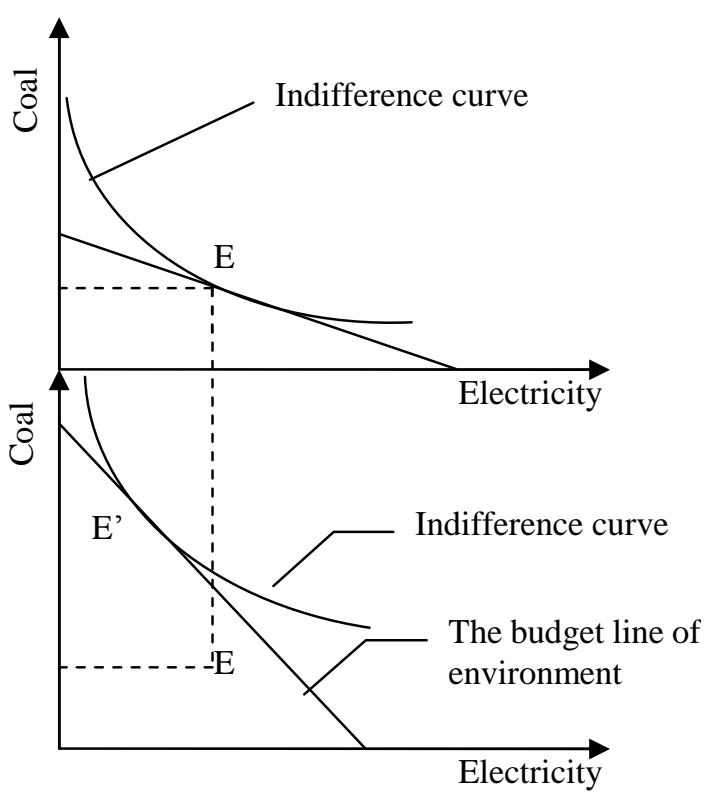

Fig.5 Choice in a dilemma

Obviously the consumer chooses point $\mathrm{E}$ (the point at which its indifference curve is tangent to its budget line). At the same time suppose consuming energy will do harm to environment. $\mathrm{C}_{1}$ is the losing of environment per coal consumed, $\mathrm{C}_{2}$ is the losing of environment per electricity consumed, and the $\mathrm{n}$ is the volume of environment damaged that the government can accept. The budget line of environment likes Eq. 16, and the consumer chooses point E' (the point at which its indifference curve is tangent to its budget line of environment)

$\mathrm{C}_{1} \mathrm{X}_{1}+\mathrm{C}_{2} \mathrm{X}_{2}=\mathrm{n}$

Now the question is whether the makeup of point $E$ is same as point $E$ '. In fact most people believe that it is difficult to have a same point. It means that the consumer likely has a good choice in economy, but he has a bad choice in environment.

What should government do at this time? One is changing price of coal or electricity, the other is urging development of technology that make consumer give less damage to environment when he uses energy. Obviously the last one is the best way to solve the problem.

\section{Policy of Encouraging Consumer Using Cleanly Energy Resources}

As is well known, most Chinese cities rely heavily on coal, but not other cleanly energy. Why consumers not use cleanly ones? The reason lies in externality and sunk cost. Due to the social cost are not counted, the price of some conventional energy, such as coal, is relative low to consumers. In order to use some energy resource, we must invest heavily in infrastructure. If we make changes of the urban energy structure, the cost will be very high, so the government or consumer would not like to change. Some policies should be passed to spur them. A feasible one is government provides subsidy to new energy consumer and raises the price of polluted energy to eliminate the externalities.

\section{Conclusion}

In this paper, three types of relationship, including relationship between energy and resident life, relationship between energy and urban growth and relationship between energy and environment in a city, was established in accordance with economic theory. We can draw the following conclusion.

(1) One energy resources can be replaced by another energy resources and the pattern of consuming energy resources is not always optimum in actual life. 
(2) energy consumption and energy structure adjustment could promote urban economic growth and urban population growth.

(3) Consumers would like to choose inexpensive energy, instead of choosing environment friendly energy, because the environment friendly energy usually is expensive.

In order to promote urban growth rapidly and urban environment livable, government should provide subsidy to new energy consumer and raises the price of polluted energy to eliminate the externalities.

\section{References}

[1] S.J. Jia, Y. Chen, R.Z. Zhang, et al, Relationship among Energy Footprint, Urban Expansion and Economic Development in Henan Province, Areal Res. Dev. 34 (2015) 117-122. [in Chinese]

[2] Z. Li, J.E. Guo, P. Li, Empirical Analysis of Circling-layering of Urban Agglomerations on Energy Intensity, China Popul. Resour. Environ. 24 (2014) 26-32. [in Chinese]

[3] Z. Li, J.E. Guo, Urban Energy Efficiency Measurement: Methods and Evaluations, Ecol. Econ. 31 (2015) 23-27. [in Chinese]

[4] M. Croucher, Potential problems and limitations of energy conservation and energy efficiency, Energ. Policy 39 (2011) 5795-5799.

[5] L.J. Zhang, G.J. Liu, Y.C. Qin, Multi-scale integrated assessment of urban energy use and $\mathrm{CO}_{2}$ emissions, J. Geogr. Sci. 24 (2014) 651-668.

[6] K. Schiel, O. Baume, G, Caruso, et al. GIS-based modelling of shallow geothermal energy potential for $\mathrm{CO}_{2}$ emission mitigation in urban areas, Renew. Energ. 86 (2016) 1023-1036.

[7] Y.L. Yao, Analysis of Bejing Urban Development Factors on Energy consumption, China Popul. Resour. Environ. 21 (2011) 40-45. [in Chinese]

[8] V. Gaigalis, R. Skema, Analysis of the fuel and energy transition in Lithuanian industry and its sustainable development in 2005-2013 in compliance with the EU policy and strategy, Renew. Sustain. Energ. Rev. 52 (2015) 265-279.

[9] H.T. Pao, H.P. Chen, Y.Y. Li, Competitive dynamics of energy, environment, and economy in the U.S., Energy 89 (2015) 449-460.

[10] U. Eicker, D. Monien, E. Duminil, et al, Energy performance assessment in urban planning competitions, Appl. Energ. 155 (2015) 323-333.

[11] A. Kylili, P.A. Fokaides, European smart cities: The role of zero energy buildings, Sustain. Cities Soc. 15 (2015) 86-95.

[12]Z.Y. Tang, X.G. Ma, Economic impacts of energy supplying. J. U. Shanghai Sci. Techn. 26 (2004) 31-34. 